\title{
Sobre el origen de la tradición hispanoamericana de los derechos humanos
}

\author{
Jesús Antonio de la Torre Rangel*
}

\begin{abstract}
Sumário: Indroducción; 1. Las dos concepciones teóricas sobre los derechos humanos: la de la Ilustración y la hispanoamerica; 2. E1 descubrimiento del otro hombre; 3 . La teoría y la práctica jurídica, como defensa de los derechos de los pobres, del inequívocamente otro; 4. La raigambre bíblica de los derechos humanos, en la tradición teórica hispanoamericana; 5 . Genealogía de la concepción teórica hispanoamericana de los derechos humanos.
\end{abstract}

\section{Introducción.}

En su tratado o relección De Dominio Infidelium et Iusto Bello, Alonso de la Veracruz escribe:

"De esta octalva conclusión se sigue que el Virrey y los Oidores, obraron. injustamente cuando en tierra donde se cultiva gossypium que llamamos algodón, se imponen los tributos en vestidos, o lienzos elaborados, o tejidos con dicha materia, lo cual es contra el derecho y la justicia. Es claro: porque, aunque en la tierra haya algodón, sin embargo no hay lienzos o sabanas, que llaman mantas, y que las mujeres tejen con enorme trabajo, y gran peligro para su cuerpo y para su alma:"

"Yo vi y no solo una vez que las mujeres trabajan en esto día y noche, encerradas por fuerza y violencia en un lugar como si estuvieran condenadas a la cárcel y con sus niños que están nutriendo. Y de tal reclusión se sigue que si están embarazadas sufran aborto a causa del excesivo trabajo; si amamantan y debido a que trabajan demasiado y comen mal y fuera de hora, dan a sus hijos una leche pésima y así estos mueren. Y ahí mismo los hombres que dirigen este tipo de trabajos tienen ocasión de ofender a Dios. Hablo por experiencia, porque vi estas cosas que tan injustamente se hacen, pues se les señala la tarea, se les da la medida de ancho y largo, y tejen tan fuertemente y las hiladas deben ser tan apretadas y compactas que difícilmente podría pasar una aguja."

* Professor da Universidad de Aguas Calientes, México.

Revista da Faculdade de Direito da UFPR, Curitiba, a. 29, n. 29, 1996, p. 9-37 
"Estas cosas y otras aún mayores son fruto de tal tributo, quienes exigen esas cosas pecan y están obligados a restitución, porque de acuerdo al mandato del emperador sólo están obligados a dar el algodón y nada más."

Como botón de muestra, este texto del ilustre agustino, se inscribe de lleno en la tradición teórica de los derechos humanos hispanoamericana.

En efecto, teniendo como base un reconocimiento implícito de la dignidad humana, defiende los derechos, es decir aquello que les pertenece a las comunidades de indios; aquello que no están obligados a pagar y que se les exige por la fuerza; y esa exigencia injusta lleva a la opresión de los más débiles: las mujeres y los niños; las primeras son explotadas en el trabajo de manera brutal y reciben vejaciones sexuales; los niños, sus hijos, mueren o viven en condiciones deplorables. En el texto de Veracruz hay una defensa de los derechos humanos, pero desde la óptica de los pobres: los indios, sus mujeres y sus niños.

La explotación es "contra el derecho y la justicia" dice Alonso, esto es, contra el "mandato del emperador", como derecho objetivo o ley; pero es también contra justicia, es decir, contra lo que es del otro, contra su derecho, contra la cosa o conducta que se le debe; y contra la facultad o poder moral que tiene sobre lo suyo, contra su derecho, pues.

Sobre esta concepción de los derechos humanos nos ocuparemos en adelante.

\section{Las dos concepciones teóricas sobre los derechos humanos: la de la llustración y la hispanoamericana.}

Entre el 29 de mayo y el 2 de junio de 1537, el papa Paulo III dio tres documentos de enorme importancia para la Iglesia indiana en general y para la Iglesia novohispana en particular; tres documentos que implican la defensa de los derechos de los indios: la Pastorale Officium, la bula llamada Altitudo divino consillii y la encíclica Sublimis Deus, siendo esta última una auténtica declaración de derechos inherentes a todos los hombres y de libertad de los pueblos. La encíclica Sublimis Deus era producto del pensamiento y la acción de varios misioneros indianos; en su inspiración y

1 Alonso de la Veracruz. Sobre la Conquista y los Derechos de los Indígenas, texto íntegro en castellano del tratado De Dominio Infidelium et Iusto Bello. Trad. Rubén Pérez Azuela, O.S.A. Ed. Organización de Agustinos de Latinoamérica (OALA). México, 1994. Parágrafos 212, 213 y 214. p. 65. 
solicitud al papa, destacan las siguientes intervenciones: informes y acciones concretas del dominico Bernardino Minaya; una célebre carta del primer obispo de Tlaxcala, el dominico Julián Garcés; una carta del obispo de México, el franciscano Juan de Zumárraga; varios escritos del dominico fray Bartolomé de las Casas, destacando su primer libro conocido como $\mathrm{Del}$ único modo; y las opiniones vertidas por los obispos y religiosos novohispanos en las juntas apostólicas de mediados de 1536, celebradas en la ciudad de México.

La encíclica Sublimis Deus, es, sin duda, una primera declaración universal de derechos humanos, producto de un reconocimiento previo de esos derechos, hecho por un puñado de misioneros que supieron reconocer en el indio al otro hombre, esto es a seres distintos de ellos, pero tan seres humanos como ellos mismos. Se trata de un fruto ya maduro, que implica el comienzo de la consolidación de la teoría hispanoamericana de los derechos humanos.

Aunque ya en varios trabajos lo hemos expresado, ${ }^{2}$ resulta oportuno reiterar aquí el hecho de que durante una mesa de trabajo en el "II Seminario La Universidad y los Derechos Humanos en América Latina," celebrado en la Universidad Iberoamericana de la ciudad de México en noviembre de 1990, le escuchamos al padre José Aldunate de la Compañía de Jesús hacer una certera afirmación cuando dijo que sobre los derechos humanos existen dos tradiciones teóricas: la de la Ilustración, ligada a la Revolución francesa y a la Independencia de Estados Unidos, de corte eminentemente individualista; y otra tradición que nace en América Latina con Bartolomé de las Casas y el grupo de los primeros evangelizadores que pensaban como él, caracterizada por concebir los derechos humanos a partir del pobre. ${ }^{3}$ Hasta aquí las importantes palabras de Aldunate.

Cada una de esas tradiciones teóricas sobre los derechos humanos tiene una filosofía jurídica en la cual hunde sus raíces.

La de la Ilustración apela teóricamente a la llamada Escuela del Derecho Natural, que se desarrolla a lo largo de los siglos XVII y XVIII;

2 Cfr. Jesús Antonio de la Torre Rangel. El uso alternativo del Derecho por Bartolomé de Las Casas. Ed. Universidad Autónoma de Aguascalientes. Aguascalientes, 1991. págs. 174-175.

3 Esta afirmación la hizo el jesuita chileno en la Mesa 6-1 sobre Investigación, el 9 de noviembre de 1990. Cfr. "Los Derechos Humanos y la Iglesia Chilena", en La Universidad y los Derechos Humanos en América Latina. Ed. Unión de Universidades de América Latina y Comisión Nacional de Derechos Humanos. México, 1992. págs. 123-129.

Revista da Faculdade de Direito da UFPR, Curitiba, a. 29, n. 29, 1996, p. 9-37 
es de corte racionalista y su principio social fundamental es el individualismo.

La segunda es más antigua y se trata del jusnaturalísmo de tradición cristiana que tiene su expresión más acabada con los teólogos juristas españoles del siglo XVI y principios del siglo XVII tales como Vitoria, De Soto, Suárez y Mariana; conlleva una concepción del Derecho Natural no sólo racional, sino que tiene en cuenta al hombre concreto y a la historia y con un principio social fundamental de corte comunitario.

Esta corriente del jusnaturalismo cristiano, da el salto definitivo en la concepción de los derechos humanos desde el pobre, no en las cátedras españolas, sino en la práxis de la defensa del indio y a partir de la realidad de las Indias.

Los distintos fundamentos filosóficos de una y otra corriente hacen que existan entre ellas enormes diferencias. El hecho de que se den, entre una y otra teoría de los derechos humanos, fundamentos distintos, necesariamente implica el que se llegue a distintas consecuencias también. No es, como optimísticamente se pudiera afirmar, que por distintos caminos se llega a lo mismo, esto es, el reconocimiento y aceptación de los derechos del ser humano.

Las dos concepciones de los derechos humanos que nos ocupan, tanto la de la Ilustración como la hispanoamericana, reconocen la existencia del Derecho Natural más allá del Derecho Positivo; ambas se inscriben, pues, dentro de la tradición muy general del jusnaturalismo. Sin embargo, la primera, como dijimos, tiene sus raíces en la llamada Escuela del Derecho Natural, que está constituida por un jusnaturalismo profano, eminentemente racionalista, propio del Iluminismo; y la segunda, tiene su base en el jusnaturalismo clásico retomado por la tradición filosófica cristiana.

Explicitemos más las diferencias entre la Escuela o Doctrina del Derecho Natural y el jusnaturalismo clásico; esas diferencias son:

$1^{\circ}$. - La Escuela del Derecho Natural se funda sólo en la razón. Es racionalista. La clásica, en cambio, se funda en un determinado concepto global del hombre, en una antropología integral, no sólo en la razón. Messner escribe que "la ciencia del Derecho natural no se puede contentar con el conocimiento natural que tiene la razón humana de los principios elementales morales y jurídicos, sino que le es imprescindible penetrar en 
el ser, es decir, en la naturaleza de la cosa y sobre todo en la naturaleza del hombre". 4

$2^{\circ}$.- La Escuela del Derecho Natural es ahistórica, por principio el Derecho es el mismo e igual "para todos, en todo tiempo y lugar".

La clásica, si bien se ha concebido en algunas ocasiones como si fuera ahistórica y tiene siempre el peligro de la ahistoricidad, sus más claros exponentes, sin embargo, dejan un camino abierto parạ su adaptación histórica.

$3^{\circ}$. - La Escuela del Derecho Natural carga el acento en el individualismo. La clásica, sin olvidar al individuo, acentúa la importancia de la comunidad.

$4^{\circ}$.- Por último, el jusnaturalismo clásico de raíz cristiana tiene implícito el concepto bíblico del Derecho como Mispat, esto es, como liberación del oprimido, lo que se hace muy claro, y a veces hasta explícito, en el salto teórico-práxico de esta corriente dado en Indias, en América, precisamente en su nacimiento, al concebir los derechos humanos desde el pobre. La Escuela del Derecho Natural, carace de esta concepción, a pesar de estar inscrita, de manera muy general, en la "cultura cristiana", pues lleva razón Kuri Camacho cuando escribe que "ninguna de las corrientes existentes hoy en el mundo occidental habrá enaltecido la dignidad humana, los derechos del hombre, más de lo que lo ha hecho el cristianismo. ${ }^{5} \mathrm{Y}$ en ese sentido la Ilustración es deudora de la tradición cristiana al hacer proclamación de derechos humanos, pero jamás ha entendido esos derechos desde el pobre.

La consecuencia distinta más importante, entre una y otra corriente jusnaturalista, con relación a los derechos humanos, está en que la primera, la de la Ilustración, circunscribe el ámbito de los derechos humanos al individuo, teniendo como base una reafirmación racional del yo frente al otro y sin entrañar circunstancias históricas. La clásica, en cambio, con su visión integral del hombre, concibe la existencia de los derechos humanos tanto individuales como sociales, teniendo como base una relación entre el

4 Johannes Messner. Sociología Moderna y Derecho Natural. Ed. Herder. Barcelona, 1964. p. 36.

5 Ramón Kuri Camacho. "La Declaración de los Derechos del Hombre de 1789 y la tradición judeo-cristiana", en Analogía Filosófica. Año 9 N 1 . México, enero-junio de 1995. p. 51

Revista da Faculdade de Direito da UFPR, Curitiba, a. 29, n. 29, 1996, p. 9-37 
yo y el tú, que es el nexo fundante de la justicia, y con la posibilidad de historizarse.

Estamos conscientes que la corriente del jusnaturalismo clásico en ocasiones se ahistoriza. Esto es, se queda en hermosos conceptos, en bellos enunciados, en afirmaciones de justicia y bien común, en conceptuosas palabras sobre los derechos humanos, pero todo esto sin acercarse a la realidad histórica, sin fundarse en ella.

Lo realmente interesante estriba en que, nuestra tradición hispanoamericana de los derechos humanos, tiene su enorme riqueza en el hecho de que no sólo se basa en los fundamentos teóricos del jusnaturalismo clásico, sino además en el hecho de que ésta, nuestra tradición sobre los derechos humanos, nace en concreto por una teoría y una práxis de defensa de esos derechos, y que hemos llamado jusnaturalismo histórico.

\section{El descubrimiento del otro hombre.}

La tradición teórica hispanoamericana de los derechos humanos, tuvo su inicio con la defensa que hicieron de los derechos de los indios los padres dominicos que llegaron a La Española en 1510, encabezados por fray Pedro de Córdova. Esos religiosos con la explotación y exterminio de los indios ante sus ojos, dice Las Casas,

comenzaron a juntar el derecho con el hecho...y a tractar entre sí de la fealdad y enormidad de tan nunca oída injusticia, diciendo así: '¿Estos no son hombres? ¿Con estos no se deben guardar y cumplir los preceptos de caridad y justicia? ¿Estos no tenían sus tierras propias y sus señores y señoríos? ${ }^{, 6}$

Con el objeto de denunciar la injusticia, se pusieron de acuerdo los religiosos en la prédica de los sermones con motivo de Adviento, determinando que el encargado de la homilía fuera fray Antón de Montesinos, basándose en un texto firmado por todos los frailes de la comunidad, que en su parte medular decía así:

Decid: ¿con qué derecho y con qué justicia tenéis en tan cruel y horrible servidumbre aquestos indios? ¿Con qué autoridad habéis hecho tan

6 Bartolomé de las Casas. Historia de las Indias. Ed. Fondo de Cultura Económica. México, 1981. t. II, lib. III, cap. III, p. 439. 
detestables guerras a estas gentes que estaban en sus tierras mansas y pacíficas, donde tan infinitas dellas, con muertes y estragos nunca oídos, habéis consumido?... ¿Estos, no son hombres? ¿No tienen ánimas racionales? ¿No sois obligados a amallos como a vosotros mismos?...

El descubrimiento de la alteridad, del otro, conlleva a reconocer sus derechos. El saber ver al otro, hace descubrir su dignidad, la dignidad humana, cuyo núcleo, dice Joaquín Herrera, es el derecho a tener derechos, contenido esencial de los derechos humanos. 8

En palabras de Pedro Mir, Montesinos "es el primer abanderado de la lucha por los derechos humanos en el mundo moderno". 9

Por supuesto que no todos, ni aun los juristas sabían ver al "otro". $\mathrm{Ni}$ tardas ni perezosas las autoridades y encomenderos de la Española determinaron quejarse ante el rey Fernando por la actitud de los padres dominicos. El rey condenó en principio la conducta de los frailes, ya que según el católico monarca, la prédica de los dominicos no tenía "ningún buen fundamento de teología ni cánones ni leyes", ${ }^{10}$ de acuerdo al decir de sus consejeros letrados.

Decimos que el rey Fernando condenó en principio a los dominicos, pero poco después autorizaría, como consecuencia de la denuncia de estos frailes, la expedición de las primeras ordenanzas para el tratamiento de los indios, conocidas como Leyes de Burgos, de diciembre de 1512; las que, sin constituir un texto que satisfaga en plenitud el reconocimiento y goce de los derechos humanos, se trata de una legislación que en materia laboral es sumamente avanzada para su época. Ya hubieran querido muchos obreros en la formación social capitalista, a fines del siglo XVIII y durante todo el $\mathrm{XIX}$, tener varias de las normas proteccionistas establecidas en estas ordenanzas.

7 Idem Supra. págs. 441 y 442.

8 Joaquín Herrera Flores. Los derechos humanos desde La Escuela de Budapest. Ed. Tecnos. Madrid, 1989. p. 128.

9 Pedro Mir. "Vigencia de Las Casas en el pensamiento americano". En el Quinto Centenario de Bartolomé de las Casas. Ed. Cultura Hispánica, Instituto de Cooperación Tberoamericana. Madrid, 1986. p. 58.

10 Carta del rey Fernando a Diego Colón de 20 de marzo de 1512, transcrita por Silvio Zavala. La encomienda indiana. Ed. Porrúa. México, 1973. p. 21. 
Desde la filosofía de la liberación, Enrique Dussel ha escrito recientemente:

En 1492, según nuestra tesis central, es la fecha del "nacimiento" de la Modernidad... nació cuando Europa pudo confrontarse con "el otro" que Europa y controlarlo, vencerlo, violentarlo; cuando pudo definirse como un "ego" descubridor, conquistador, colonizador de la alteridad constitutiva de la misma modernidad. De todas maneras, ese otro no fue "descubierto" como otro, sino que fue "encubierto" con "lo mismo" que Europa ya era desde siempre. ${ }^{11}$

Usando estas mismas categorías de pensamiento, nosotros sostenemos que los que no encubrieron al otro, sino que lo descubrieron, hicieron posible una tradición amplia de la concepción de los derechos humanos. Al afirmar la alteridad, superion ver que las acciones del conquistador eran injustas pues iban en agravio, violentaban los derechos del indio descubierto como otro.

El encubridor y el descubridor del otro, tienen ante la misma realidad una visión opuesta.

El siguiente texto de Juan Ginés de Sepúlveda -jurista consejero de la Corte y acérrimo enemigo de Las Casas-, constituye el fundamento teórico de la opresión, del encubrimiento de la alteridad, del otro como otro:

Bien puedes comprender joh Leopoldo! si es que conoces las costumbres y naturaleza de una y otra parte, que con perfecto derecho los españoles imperan sobre estos bárbaros del Nuevo Mundo e islas adyacentes, los cuales en prudencia, ingenio, virtud y humanidad son tan inferiores a los españoles como los niños a los adultos y las mujeres a los varones, habiendo entre ellos tanta diferencia como la que va de gentes fieras y crueles a gentes clementísimas, de los prodigiosamente intemperantes a los continentes y templados, y estoy por decir que de monos a hombres... ¿Qué cosa pudo suceder a estos bárbaros más conveniente ni más saludable que el quedar sometidos al imperio de aquellos cuya prudencia, virtud y religión los han de convertir de bárbaros, tales que apenas merecían el nombre de seres humanos, en hombres civilizados en cuanto pueden serlo; de torpes y libidinosos, en probos y honrados, de impíos y siervos de los demonios, en cristianos y adoradores del verdadero Dios?... Por muchas causas, pues, y muy graves, están obligados estos bárbaros a recibir el imperio de los

11 Enrique Dussel. 1492. El encubrimiento del otro. El origen del mito de la modernidad. Ed. Antropos. Santafé de Bogotá, 1992. págs. 11 y 12. 
españoles conforme a la ley de naturaleza, y a ellos ha de serles todavía más provechoso que a los españoles, porque la virtud, la humanidad y la verdadera religión son más preciosas que el oro y que la plata. ${ }^{12}$

Estas mismas palabras, adaptadas a cada circunstancia histórica, son el fundamento ideológico de todo conquistador-opresor. Triple discurso opresivo: los conquistadores superiores a los conquistados que son casi como "monos"; los adultos superiores a los niños; las mujeres inferiores a los varones. Y todo esto coronado por la fetichización de la religión, pues de impíos a "adoradores del verdadero Dios".

Bartolomé de las Casas ante la misma realidad histórica, pero descubriendo al otro, escribe:

... porque de derecho divino es ordenado y mandado que para que los hombres vaquen a las cosas divinas y se ejerciten en las cosas de cristianos... tengan paz y tranquilidad, y sean conservados en ella, la cual se alcanza y se conserva con la guarda de la justicia, conviene a saber, dejando y no tomando a cada uno lo suyo, y conservándole su derecho sin hacerle injuria ni injusticia alguna... Y porque... los cristianos, por sus grandes cudicias, no pueden estar ni les es posible, teniendo señorío particular o interese en los indios, dejarlos de afligir, injuriar, turbar, agraviándolos, inquietándolos... tomándoles sus pobres haciendas, sus tierras, sus mujeres, sus hijos, y haciéndoles otras muchas maneras de injusticias... 13

Las Casas sí ve las injusticias y sí rescata los derechos de los indios frente a los españoles. Los indios son seres humanos, no animales y no hay jerarquías entre unos y otros: todos son iguales.

Sepúlveda encubre los derechos del otro; Las Casas los descubre. Siguiendo al primero no puede haber fundamento alguno de los derechos humanos; de acuerdo a lo que dice el segundo sí.

12 Juan Ginés de Sepúlveda. Tratado sobre las justas causas de la guerra contra los indios. Ed. Fondo de Cultura Económica. México, 1987. págs. 101, 133 y 134.

13 Bartolomé de las Casas. "Octavo remedio" (tratado sexto), Tratados. Ed. Fondo de Cultura Económica. México, 1974, t. II, págs. 677 y 679.

Revista da Faculdade de Direito da UFPR, Curitiba, a. 29, n. 29, 1996, p. 9-37 


\section{La teoría y la práctica jurídica, como defensa de los derechos de los pobres, del inequívocamente otro.}

Los fundadores de la teoría de los derechos humanos hispanoamericana no sólo descubren la exterioridad, la alteridad, el ámbito del otro, sino que colocan de plano, de manera radical, su teoría y su práctica jurídica de defensa de los derechos humanos, en el inequívocamente otro, es decir en aquellos que provocan a la justicia, precisamente, porque padecen la injusticia, porque históricamente les son negados sus derechos. Dussel escribe:

"El derecho del otro, fuera del sistema, no es un derecho que se justifique por el proyecto del sistema o por sus leyes. Su derecho absoluto, por ser alguien, libre, sagrado, se funda en su propia exterioridad, en la constitución real de su dignidad humana". ${ }^{14}$

El fundamento de todo derecho es la dignidad del hombre; el hecho de ser el otro, libre e inmanipulable. Al fin y al cabo, los derechos humanos no son otra cosa que la juridificación de la dignidad humana.

"El otro, el pobre en su extrema exterioridad del sistema, provoca a la justicia; es decir llama (-voca) desde delante (pro-)."15

Si todo derecho viene fundado en la dignidad del otro, del ser humano como tal, la justicia viene solicitada por el que no la tiene, por el que padece la injusticia, por el pobre, por el inequivocamente otro -en palabras de Dussel-.

La base filosófica de la teoría de los derechos humanos hispanoamericana, tiene su origen, hemos dicho, en el jusnaturalismo clásico recogido y reelaborado por la tradición cristiana, con su expresión más acabada de los teólogos juristas españoles del siglo XVI y principios del siglo XVII.

Así por ejemplo, Francisco de Vitoria, el ilustre dominico profesor de la Universidad de Salamanca, en bellas palabras expresa el postulado de la dignidad del hombre, al considerarlo como poseeedor de derechos en cuanto que puede padecer injuria. ${ }^{16}$

14 Enrique Dussel. Filosofia de la Liberación. Ed. Edicol. México, 1977. p. 53.

15 Idem Supra.

16 Las relecciones juridicas de Vitoria. Ed. Jus. México, 1947. p. 69, introducción y notas de Rafael Aguayo Spencer. 
Sin embargo, hemos afirmado también que esta corriente jusnaturalista da el salto definitivo en su concepción de los derechos humanos, en la práxis de la defensa del indio y a partir de la realidad de las Indias.

Se trata de una concepción de los derechos humanos, como hemos insistido, con los fundamentos del jusnaturalismo clásico notablemente enriquecido por los autores cristianos, pero con la ventaja enorme de que está concebida desde el pobre, desde aquel que sufre sistemáticamente, estructuralmente, la violación de sus derechos. Esto es, se historizan, se hacen históricos los conceptos de la justicia, el bien común y los derechos humanos, porque se confrontan con una realidad concreta. Parten del descubrimiento del otro, por el sólo hecho de ser hombre portador del derecho a tener derechos, y por ser oprimido provocador de la justicia concreta.

La defensa de los derechos de los indios hace surgir, pues, nuestra tradición teórica de los derechos humanos, con un ejercicio teórico y práctico de lo que hemos llamado jusnaturalismo histórico. Toda la conceptualización de justicia, bien común y derechos del ser humano de la Escuela de Salamanca, se confronta con la realidad histórica de la tremenda violación a los derechos de los indios por parte de los conquistadores. Y es así que surge nuestra tradición teórica sobre los derechos humanos, al teorizar y practicar sobre la defensa de esos derechos ultrajados en las personas y pueblos de los aborígenes de América.

El profesor Barp nos proporciona el concepto de justicia de Alonso de la Veracruz, producto de la antropología filosófica del pensador novohispano; se trata de una concepción de la justicia que prepara al jusnaturalismo histórico, le sirve de base:

"¿Qué te debo? A esta pregunta nunca se puede contestar 'no te debo nada'. A esta pregunta '¿qué te debo?' siempre se debe contestar 'te debo todo', es decir 'te debo todo lo que eres'."17

17 Luciano Barp Fontana. "Pensamientos Liberadores de Alonso de la Vera Cruz, en el Speculum Coniugiorum (espejo de los casamientos)", en Memoria IV Encuentro Nacional de Investitgadores de la Filosofía Novo Hispana. Ed. Universidad Autónoma de Aguascalientes e Instituto de Investigaciones Filológicas de la Universidad Nacional Autónoma de México. Aguascalientes, octubre de 1992. p. 272.

Revista da Faculdade de Direito da UFPR, Curitiba, a. 29, n. 29, 1996, p. 9-37 
Qué extraordinario concepto de justicia construido, en su contenido, en lo que el hombre es y que implica ser portador de todos los derechos que le deben ser respetados.

Esto llevado a la realidad de la explotación de los indios, implica un razonamiento como el que Bartolomé de Las Casas hace al convertirse a la defensa de sus derechos, una reflexión de aplicación del jusnaturalismo histórico. En efecto, en el sermón en que el dominico anuncia que dejará sus negocios y se pone claramente en favor de los derechos de los débiles, hace una sugerente reflexión jurídica, pues pone como centro

"su ceguedad, injusticias y tiranías y crueldades que cometían en aquellas gentes inocentes",

y les hace manifiesto a sus oyentes

"la obligación a restitución en que estaban ligados"18 para con los indios. Y esto había naeido en su mente y corazón, a partir de su reflexión y su sentir,

"por lo que leía cuanto al derecho y vía de hecho, aplicado lo uno a lo otro, determinó en sí mismo convencido de la misma verdad, ser injusto y tiránico todo cuanto cerca de los indios en estas Indias se cometía".

\section{La raigambre bíblica de los derechos humanos, en la tradición teórica hispanoamericana.}

Hemos dicho que los primeros evangelizadores indianos concibieron los derechos humanos a partir del pobre. $Y$ esto tiene un fundamento bíblico.

Dios aparece en la Biblia como el protector del más débil y asegura el respeto de sus derechos. En los Proverbios se identifica la ofensa hecha al pobre con la ofensa hecha a Dios (Prov. 14,31), misma idea religiosa que recoge Jesús de Nazareth (Mateo 25, 31-46). "Dios es liberador y redentor, por lo tanto, garante de aquellos a quienes el mundo no reconoce o respeta sus derechos" 20 escribe Hugo Echegaray. Y agrega: "Dios aparece

18 Las Casas. Historia de las Indias. Lib. III. Cap. LXXIX, en el Tomo III. Ob. cit. p. 95.

19 Idem Supra. p. 93.

20 Hugo Echegaray. Derecho del Pobre; Derecho de Dios. Ed. Centro de Reflexión Teológica. México, 1982. págs. 15 y 16. 
desprovisto de imparcialidad frente a la historia. Porque Dios es soberanamente justo, Dios es parcial". ${ }^{21}$ Lo inusitado de esta concepción jurídica de la Biblia, sigue diciendo el teólogo peruano, es "la conciencia de una especie de derecho -escandaloso para los bien pensantes- del pobre a ser amado por Dios". 22

José M. Chacón y Calvo escribió, en referencia al sermón de Montesinos, producto de la reflexión de la pequeña comunidad dominica de La Española:

"En aquellos momentos solemnes, en la humilde residencia de unos oscuros frailes surgía un Derecho nuevo. Un Derecho de profunda raíz teológica". ${ }^{23}$

Gustavo Gutiérrez añade que ese Derecho nuevo, que nace con el sermón de Montesinos, es sobre todo de raíz bíblica, y en eso radica su fuerza."

No intentamos establecer una fácil oposición entre fundamentos teológico-jurídicos por un lado y demandas evangélicas por el otro, pero creemos que es importante hacer ver su diferencia en hondura y alcance; en efecto, sin las últimas los primeros no son colocados en su contexto propio y vital. Las diversas preguntas de la homilía de Montesinos están ligadas, es cierto, pero aquella que recuerda la calidad del prójimo que tiene el indio para los misioneros, y el consiguiente deber de amarlo, es la que va más lejos y da sentido a todo el conjunto". ${ }^{24}$

Es aquí en donde aparece con claridad el salto de la concepción de los derechos hispanoamericana a partir del pobre. Los teólogos juristas españoles, especialmente la Escuela de Salamanca, se quedan en el reconocimiento pleno de la dignidad humana de todos los hombres por igual; los misioneros, partiendo de esta premisa, ven la diferencia real, histórica, que existe entre el poderoso y el débil, el conquistador y el conquistado, y optan, por su entender el Derecho según la Biblia, por el débil frente al poderoso.

21 Idem Supra. p. 16.

22 Idem Supra. págs. 20 y 21.

23 Citado por Venancio Carro, O.P. en La Teologia y los teólogos-juristas españoles ante la Conquista de América. Ed. Biblioteca de Teólogos Españoles. Salamanca, 1951. p. 1.

24 Gustavo Gutiérrez. En busca de los Pobres de Jesucristo. El Pensamiento de Bartolomé de Las Casas. Ed. Instituto Bartolomé de Las Casas-Rimac y Centro de Estudios y Publicaciones. Lima, 1992. p. 50 .

Revista da Faculdade de Direito da UFPR, Curitiba, a. 29, n. 29, 1996, p. 9-37 
Cuando en los años de 1550 y 1551 disputa Las Casas con Juan Ginés de Sepúlveda en la famosa Junta de Valladolid, su tesis fundamental es que la guerra de los cristianos contra los indios en injusta y radicalmente en contra de la caridad crịtiana. ${ }^{25}$ Lassègue llama la atención en que, precisamente en el punto de la guerra, el dominico se aparta de la Escuela de Salamanca que la trata en lo relativo a la justicia, y retoma a Santo Tomás de Aquino que la ubica en el tratado de la caridad. ${ }^{26}$

Esta idea lascasiana de relacionar, en una polémica filosófico-jurídica, la caridad con la materia propia del Derecho, muestra con claridad la concepción que tienen de los derechos humanos los principales defensores de los derechos de los indios -encabezados ciertamente por Las Casas-, y que es de la más pura tradición bíblica como mispat, esto es, como liberación del oprimido.

En la tradición bíblica, y más concretamente en la profética, el Derecho y la justicia no son conceptos distintos de la caridad. Lo jurídico implica de manera directa el rescate del pobre, del oprimido; no se trata del concepto aristotélico de justicia distributiva, legal y conmutativa, sino de la salvación plena de la dignidad del hermano que ha sido ultrajado, de la reivindicación del que ha sido oprimido, empobrecido. En otras palabras, derecho y justicia implican la liberación del otro, el hacerse responsable del hermano débil; el hacer práxis de caridad, quiero decir. ${ }^{27}$

Los defensores de los derechos de los indios de la primitiva Iglesia novohispana tienen esta concepción bíblica del Derecho y de los derechos humanos. Ciertamente no elaboran -quizás ni siquiera Las Casas ni Veracruz-, una doctrina sistemática acerca de losderechos humanos; ni hacen un largo catálogo -como hoy se usa- de esos derechos del hombre; pero sí, basados en su tradición fílosófica y radicalmente cristiana, descubren la dignidad humana del otro distinto del conquistador.

En la primera parte de este trabajo, al referirnos a la naciente Iglesia Novohispana, hemos hablado de muchas acciones de teoría y práctica

25 Cfr. Juan Ginés de Sepúlveda y Bartolomé de Las Casas. Apología. Traducción Angel Losada. Ed. Nacional. Madrid, 1975.

26 Cfr. J. B. Lassègue. La Larga Marcha de Las Casas. Ed. Centro de Estudios y Publicaciones. Lima, 1974. p. 328.

27 Sobre este tema puede verse: Porfirio Miranda. Marx y la Biblia. Crítica a la Filosofia de la Opresión. México, 1971; José Luis Sicre. Con los Pobres de la Tierra. La Justicia Social y en los Profetas de Israel. Ed. Cristiandad. Madrid, 1984; y la obra citada de Hugo Echegaray. 
jurídica en defensa de los derechos humanos en general y de los indios en particular, por parte de los obispos como Protectores de los indios y de las Juntas Eclesiásticas. En todas esas acciones se manifiesta con claridad como se va gestando, como va tomando forma, esa concepción de los derechos humanos, con las características que le hemos señalado a la tradición teórica hispanoamericana.

\section{Genealogía de la concepción teórica hispanoamericana de los derechos humanos.}

Hablar de una tradición teórica hispanoamericana de los derechos humanos, en el sentido que la hemos descrito, no es unánimemente aceptado. Lejos de ello, muchos historiadores sólo réconocen la tradición teórica de los derechos del hombre de la Ilustración, y sitúan, por lo tanto, "el comienzo de los derechos humanos entre los siglos XVII y XVIII en Inglaterra, Francia y las colonias inglesas de América del Norte." ${ }^{28}$ En esa posición, actuando -como él mismo dice- "de abogado del diablo", Bartolomé Clavero niega la existencia de los derechos humanos en la América Española, en un trabajo presentado en un seminario precisamente sobre la tradición indiana y los derechos humanos. El profesor de la Universidad de Sevilla dice:

"Recordemos ante todo algo tan básico como que los derechos, rigurosamente los derechos, no existían entonces para nadie. Los juristas, siguiendo a los teólogos, no admitían derechos en su sentido subjetivo, esto es facultades de sujetos, por sí mismos y para ningún caso; esto no entraba en los supuestos de la cultura del tiempo; era algo entonces inconcebible. De entrada, a nadie, ni a colonizador ni a colonizado sin ir más lejos, se le reconocía capacidad alguna de título originario y disposición propia. El derecho comenzaba por ser, no facultad de un titular, sino ordenamiento de la sociedad. Tenía ante todo este sentido de orden objetivo." 29

Clavero ubica el nacimiento de los derechos humanos "hasta mediado el siglo XVII y por latitudes de momento tan sólo británicas."30

28 Fernando Rovetta Klyver. "Hacia un modelo iberoamericano de derechos humanos a partir de Francisco de Vitoria y de la legislación indiana", en Los Derechos Humanos en América. Una perspectiva de cinco siglos. Ed. Cortes de Castilla y León. Salamanca, 1994. p. 153.

29 Bartolomé Clavero. "Espacio colonial y vacío constitucional de los derechos indígenas", en Anuario Mexicano de Historia del Derecho VI-1994. La Tradición Indiana y el origen de las declaraciones de derechos humanos. Ed. Universidad Nacional Autónoma de México. México, 1994. p. 67.

Revista da Faculdade de Direito da UFPR, Curitiba, a. 29, n. 29, 1996, p. 9-37 
Y agrega que: "De entonces, solamente de entonces, viene la ocurrencia que hoy nos puede parecer tan sencilla del individuo como sujeto originario del derecho." 31

No estamos de acuerdo con la postura de Clavero. Creemos que el movimiento de la Ilustración, acompañando a los cambios sociales y políticos de su entorno, genera una juridificación en términos modernos de lo que se há denominado derechos humanos, pero la concepción de éstos es anterior a la mitad del siglo XVII, y que precisamente existe un momento histórico muy anterior, precisamente la primera mitad del siglo XVI, en que éstos se reconocen y forman parte de la juridicidad de su tiempo, no sólo como derechos de los individuos sino también como derechos de los pueblos o comunidades.

Rovetta Klyver escribe:

“... porque considero que durante la conquista y colonización de América -sobre todo en las primeras décadas- ocurrieron actos 'inhumanos, atroces y aberrantes', llegando incluso al 'genocidio', empleando términos actuales, es que en esa época, como en un juego dialéctico, frente a la tesitura fáctica, se pudo generar una antítesis desde la teoría ética lo suficientemente humanitaria como para inspirar leyes que pueden ser consideradas, en su intento de síntesis, expresión de lo que hoy denominamos derechos humanos. ${ }^{, 32}$

Clavero insiste:

“... no creo que vayamos a encontrar unos derechos perdidos, los derechos humanos, ni incipientes ni formados, en la tradición indiana....,33

Conscientes de lo complejo de la temática y lo polémico de esta cuestión, sin embargo nos atrevemos a sostener, en contra de la opinión de Clavero, que los derechos en el mundo indiano no están perdidos y que sí aparecen, a veces incipientes y a veces bien formados, sólo que dentro de una formación social distinta a la de los estados individualistas liberales que se establecerán muchos años después. Esos derechos aparecen teóricamente reconocidos, éticamente sostenidos y muchos de ellos

30 Idem Supra. p. 75

31 Idem Supra.

32 Rovetta. Ob. cit. p. 154

33 Clavero. Ob. cit. p. 84. 
objetivizados normativamente por la legislación dada y aplicada por el Estado.

Del tratado De Dominio Infidelium de Alonso de la Veracruz, es importante traer aquí algunos conceptos para reforzar nuestras afirmaciones. La tercera Cuestión o Duda que despeja Veracruz en su obra, la plantea así:

"En tercer lugar se duda, si acaso quien tiene dominio justo sobre un pueblo por donación regia puede a su arbitrio ocupar las tierras de los nativos cuando estén sin cultivar, pero destinadas bien sea para pastar sus ovejas o para sembrar y recolectar los frutos, etc. ${ }^{34}$

Se trata de un pueblo dado en encomienda que debe tributar al titular de la misma, y la cuestión se plantea en el sentido de si el encomendero puede ocupar caprichosamente las tierras no cultivadas del pueblo que le tributa. Antes de pasar a la respuesta que da Vercaruz a la Duda, es necesario hacer notar que, de entrada, reconoce el derecho de propiedad o dominio del pueblo a sus tierras y ese es un derecho subjetivo, un derecho humano cuyo titular es toda una comunidad, un pueblo.

La respuesta general que da el agustino a la Duda planteada es categórica:

“... nadie puede ocupar licitamente lo ajeno contra la voluntad del dueño. Como la tierra, aun cuando esté abandonada, pertenece al pueblo y no al señor que tiene derecho a los tributos. Por lo tanto, no puede ocuparla a su arbitrio." 35

Reafirma Veracruz el derecho de propiedad del pueblo, un derecho subjetivo, un derecho humano comunitario.

A lo largo de toda la respuesta a la Duda III, Veracruz reitera el derecho de los pueblos a su tierra, como un derecho anterior a la llegada de los españoles y a la instalación del señorío regio. Cierra su argumentación con una denuncią contra la injusticia, por la violación de los derechos de los pueblos:

"Estas cosas deberían causar gran escrúpulo porque sin duda los naturales sufren gran injuria y esta crece a diario; y no sólo son despojados de sus

34 Veracruz. Ob. cit. parágrafo 106. p. 41.

35 Idem Supra. Parágrafo 108. p. 41.

Revista da Faculdade de Direito da UFPR, Curitiba, a. 29 , n. 29, 1996, p. 9-37 
propias tierras, en contra de su voluntad, sino que también destruyen sus sembrados y por eso padecen hambre." 36

Ya habíamos visto que Vitoria, maestro de Veracruz en Salamanca, escribió: "Las criaturas irracionales no pueden tener dominio. Está claro, pues dominio es derecho, como confiesa Conrado; pero las criaturas irracionales no pueden tener derecho; luego ni dominio. Se prueba la menor: porque no pueden padecer injuria; luego no tienen derecho." ${ }^{37}$ Está muy clara ho subjetivo en Vitoria, lo que demuestra que la Escuela de Salamanca incluye en su teoría jurídica los derechos subjetivos, base de lo que se llama derechos humanos; como está muy clara también la concepción de esos derechos en el texto citado de Veracruz, lo que prueba que los derechos subjetivos y, por ende, los derechos humanos están presentes en la teoría y en la práxis de los hispanoamericanos.

Por otro lado, es muy importante la relación establecida entre derecho e injuria. Sólo el que puede ser agraviado, injuriado, menoscabado en su dignidad, tiene derechos; porque sus derechos tienen su fundameto en la dignidad humana, en su calidad -metafísica- de personas, de seres humanos. Esa idea esencial de Vitoria y Veracruz, de relacionar el derecho con la posibilidad de recibir injuria, nos recuerda una idea nuclear de la Filosofía del Derecho de Ernest Bloch: "La intención esencial del Derecho natural se centraba en el paso erguido como Derecho, de tal suerte que éste sea respetado en las personas y asegurado en la comunidad de ellas.",38

Reitera el agustino el derecho de los indios a "sus propias tierras" y denuncia que ese derecho no se les respeta porque "son despojados", y además, denuncia también, que destruyen "sus sembrados" dejándolos hambrientos, empobrecidos, al serles vulnerado su derecho esencial a una vida digna, síntesis de los derechos humanos.

Clavero dice también, en su papel de "abogado del diablo", que;

"La aceptación sin más de que los indígenas, gentes de otra religión o sin religión propiamente dicha, puedieran tener un derecho propio, con la secuela de que los colonizadores debieran comenzar por reconocerlo, era un punto de partida efectivamente descartado de raíz." 39

36 Idem Supra. Parágrafo 154. p 51.

37 Las Relecciones Juridicas de Vitoria. Ob. Cit. p. 69.

38 Ernest Bloch. Derecho Natural y Dignidad Humana. Ed. Biblioteca Jurídica Aguilar. Madrid, 1980. p. 212 . 
En cuanto a un "derecho propio", totalmente autónomo e independiente del Derecho objetivo indiano, ciertamente los pueblos indios no lo tuvieron, así que en una visión así de general lleva razón Clavero. Sin embargo, es necesario profundizar en la cuestión, y si hacemos ciertas acotaciones, no puede sostenerse ya esa aseveración. Es cierto, el derecho objetivo indiano, esto es la normatividad del Derecho español aplicado en Indias, se impone y, por lo tanto, el derecho objetivo de los pueblos de indios se le subordina; pero atención, el derecho objetivo (normatividad) de los pueblos indios sigue existiendo, no desaparece, sólo que está subordinado a la normatividad dominante del conquistador. Si ese derecho hubiere desaparecido, hoy no podría ser reivindicado por los pueblos indios en sus pretensiones de autonomía y respeto de sus usos y costumbres jurídicas, frente al Estado nacional. ${ }^{40}$ El Derecho Indiano mandó reiteradamente que los usos y costumbres jurídicas de los indios les debían ser respetados en todo aquello que no se opusieran a la religión católica y a la normatividad general del Estado. Esto en cuanto al derecho objetivo.

Pero además podemos sostener que varios derechos humanos les son reconocidos a los indios, aun como "gentes de otra religión o sin religión", y el más claro ejemplo es la encíclica Sublimis Deus del papa Paulo III, a la que ya hicimos alusión y que aquí volvemos a citar en su parte medular:

“... conociendo que aquestos mesmos indios, como verdaderos hombres... determinamos y declaramos que los dichos indios y todas las demás gentes que de aquí adelante vinieran á noticia de los cristianos, aunque estén fuera de la fe de Cristo, no están privados ni deben serlo de su libertad ni del dominio de sus. bienes, y que no deben ser reducidos a servidumbre..."

Y ya vimos que esa declaración tan importante de derechos, no se debe a la simple buena voluntad del viejo Papa Farnesio, sino que Dios Sublime es producto del pensamiento y la acción de varios misioneros indianos, que iban gestando la tradición teórica hispanoamericana de los derechos humanos. Precisamente ésta, nuestra concepción de los derechos del ser humano, arranca aquí, en este punto preciso de los hechos de la

39 Clavero. Ob. cit. p. 68.

40 Cfr. Jesús Antonio de la Torre Rangel. "Puntos para el Diálogo. La Insurrección del EZLN y la Juridicidad", en Revista de Investigaciones Jurídicas N 18 de la Escuela Libre de Derecho. México, 1994. págs. 259-274; y "Algunas reflexiones sobre los derechos humanos de los pueblos indios". ponencia presentada en el Coloquio "México: ¿Un proyecto nacional en crisis”, en la mesa "Derechos Humanos", en la Universidad Autónoma de Aguascalientes, el 24 de noviembre de 1995. Inédito.

Revista da Faculdade de Direito da UFPR, Curitiba, a. 29, n. 29, 1996, p. 9-37 
conquista, produciendo una ruptura con aquello que señala Clavero: se reconocen los derechos de los indios independientemente de su religión.

El profesor de la Universidad de Sevilla Bartolomé Clavero, dice que el status, el estado, "definía el derecho para el sujeto", 41 se lo determinaba. Y "el status que se da con carácter general para el caso de los indígenas es el resultante de la concurrencia entre los estados de rústico, de persona miserable y de menor. El concurso de esta tríada va a definirlo." 42

Es cierto que el status define la normatividad aplicable y el alcance de los derechos, pero precisamente también el alcance de los derechos, lo que significa que éstos eran auténticamente reconocidos. El derecho objetivo indiano, visto de una manera integral, juega respecto de los indios un doble rol -lo da el propio status en que se le ubica-: de protección, por un lado, y de sometimiento, por otro.

Pero el reconocimiento teórico y las acciones consecuentes de los postulantes hispanoamericanos de los derechos humanos, es plena, quiero decir que aceptan la protección de los indios y no su sometimiento.

Creemos, entonces, que sí podemos hablar con propiedad y sostener una concepción de los derechos humanos antes de la Ilustración, y precisamente con unos presupuestos teóricos distintos de los de esa corriente racionalista e individualista, de acuerdo a los caracteres que le hemos atribuido; esa concepción es la de la tradición hispanoamericana.

En nuestro medio es, sin duda alguna, el filósofo dominico Mauricio Beuchot, quien más se ha preocupado por sostener que los derechos humanos fueron ya plenamente concebidos por la Escuela de Salamanca y de ahí pasaron a Indias, y se hicieron vida en la práctica de los misioneros indianos, especialmente en Bartolomé de Las Casas y en Alonso de la Veracruz.

Mauricio Beuchot escribe:

41 Clavero. Ob. cit. p. 69.

42 Idem Supra. p. 70.

43 Cfr. Mauricio Beuchot. Filosofia y derechos humanos. Ed. Siglo XXI. México, 1993; Los Fundamentos de los derechos humanos en Bartolomé de Las Casas. Antropos editorial del hombre. Barcelona, 1994; "Bartolomé de Las Casas, el humanismo indígena y los derechos humanos", en Anuario Mexicano de Historia del Derecho VI-1994. Ob. cit.; "Derechos subjetivos, derechos naturales y derechos humanos", en la obra colectiva Laberintos del Liberalismo. Ed. Miguel Angel Poarrúa. México, 1995. 
"Algunos autores, como Michel Villey, Leo Strauss y Ralph MacIrerny, sostienen que los derechos humanos corresponden a los derechos naturales del iusnaturalismo moderno (p. ej. Grocio, Puferdorf y Rousseau), pero no al iusnaturalismo clásico (p. ej. Aristóteles, Justiniano y Santo Tomás). Lo anterior, ya que la noción clásica de derecho (tanto en los griegos, como en el derecho romano y en los medievales) es objetiva, es una propiedad del objeto; en cambio, la noción moderna del derecho es subjetiva, es un derecho del sujeto, una propiedad del individuo. Pero creemos que los derechos humanos sí pueden fundamentarse en un derecho natural tomista, aunque no directamente, sino a través de la escuela de Salamanca."44

Beuchot se apoya en la tesis de Blandine Barret-Kriegel, que "encuentra una vinculación con el derecho natural tomista mediante la Escuela Tomista de Salamanca, con la cual se da ese cambio de la noción de derecho objetivo a la de derecho individual: cambia la idea de ley (antes, incluso, que la idea de naturaleza)", 45 Pero nuestro filósofo dominico no sólo se apoya en la tesis de Barret-Kriegel, sino que la profundiza y la refuerza

Villey había sostenido que los derechos humanos, al ser derechos subjetivos, no pudieron tener origen en el tomismo, ya que Santo Tomás (1224-1274) tenía una noción del derecho como algo objetivo, y la Escuela de Salamanca traiciona al Aquinate al admitir la noción de derechos subjetivos; pero la profesora Barret-Kriegel "más bien se alegra de que los salmantinos hay an modificado así la noción tomista de derecho y de ley natural, porque ve en ello el surgimiento de la noción de derechos humanos." 46

\section{Y agrega Beuchot:}

"Lo que se alcanza a ver es un anticipo filosófico-teológico, aunque muy importante, de lo que después se llamarán derechos del hombre. Pero le falta dar más datos para explicar ese hecho. Las Casas es un eslabón en el paso de una noción de derecho objetivo a otra de derecho subjetivo. Lo más notable es que atiende a la dignidad del hombre y, sobre todo, a diferencia de los iusnaturalistas ilustrados, defiende los derechos naturales para todos, principalmente para los más desvalidos, como lo eran en ese caso los indios."

44 Beuchot. Filosofia y derechos humanos. Ob. cit. págs. 13 y 14

45 Idem Supra. p. 14.

46 Beuchot. "Bartolomé de Las Casas, el Humanismo Indígena y los derechos humanos". Ob. cit. p. 38. 
Bien, veamos de que manera Beuchot reconstruye la genealogía de los derechos humanos.

Comienza nuestro filósofo por recordar que los romanos decían que las cosas eran objeto de un derecho, esto era el dominium. Y esta noción de dominio pasa a Santo Tomás y a los escolásticos. "El propio Aquinate -agrega Beuchot- habla de la potestad y del dominio en el sentido que tiene el derecho subjetivo." 48

El dominico reafirma, que en el santo de Aquino sí aparecen los derechos subjetivos o personales, pero acota:

"Los derechos que Santo Tomás entiende como subjetivos pueden ser activos y pasivos. El los toma en sentido pasivo, es decir, como derechos que son dados o permiten algo por otro, más que como derechos para hacer algo uno mismo. Por eso los derechos personales, pasivos de Santo Tomás, difícilmente pueden tomarse como derechos humanos". 49

Jesús García López nos dice que Santo Tomás cuando se plantea la cuestión de la división del Derecho, no se refiere a la acepción de derecho subjetivo, "pues lo más frecuente es que a este tipo de derecho no se lo llame así, sino con los nombre de potestas, facultas, posse o licitum est."

Creemos que la noción de los derechos humanos en Santo Tomás se extrae de su noción misma de justicia, como derechos humanos pasivos según dice Beuchot. Esto porque lo suyo, el acto o la cosa, que se debe a otro en justicia, es precisamente su derecho, su derecho subjetivo, su derecho humano.

Cuando Santo Tomás trata la cuestión de la justicia dice:

"la justicia versa principalmente acerca de las cosas que se refieren a otro como a su propia materia... Y por tanto, el acto de la justicia por comparación a la propia materia y objeto se designa cuando se dice que da a cada uno su derecho; porque, como dice San Isidoro (Etym. 1. 10, letra I), dicese justo porque guarda el derecho."

47 Idem Supra.

48 Beuchot. "Derechos subjetivos, derechos naturales y derechos humanos". Ob. cit. p. 152.

49 Idem Supra. p. 153.

50 Jesús García López. Los derechos humanos en Santo Tomás de Aquino. Ed. Universidad de Navarra. Pamplonma, 1979. p. 36.

51 Santo Tomás de Aquino. Suma Teológica. T. XI. La Prudencia, la Justicia y el Derecho. Cuestión LVIII. Art. I. Versión del texto latino de Ismael Quiles. Club de Lectores. Buenos Aires, 1987. p. 117. 
Beuchot siguiendo a Villey, sostiene que la noción de derecho subjetivo, ya corriente en la Filosofía del Derecho moderna, tiene su origen en el franciscanismo medieval, en el ala nominalista de esa orden y en concreto en Guillermo de Ockham (1300-1349). ${ }^{52}$

En su Opus nonaginta dierum, Ockham, al defender a los frailes menores contra el papado, que los acusaba de herejía por querer practicar la pobreza completa, recurre para justificar la pobreza franciscana al derecho civil y eclesiástico, y analiza los conceptos de uso, usufructo, propiedad, dominio y potestad y los conecta con la noción del Derecho. "Ockham ve al derecho subjetivo como aquel en que habría poder de recurrir a la sanción establecida por la autoridad pública: 'potestad o poder de proteger y defender algo en un juicio humano.'... Al igual que Santo Tomás, define el dominium por el potestas; pero la potestas, entendida aquí como ius, hace que el derecho pase a tener un sentido subjetivo, un poder, una capacidad, una prerrogativa o una libertad." 53

Villey sostiene que Ockham, el llamado Venerabilis Inceptor, por ignorar el Derecho Romano, basó su sistema filosófico-jurídico en la noción de poder o potestad. Pero es necesario añadir que esto es posible por su propia epistemología nominalista, que radicaliza la noción del ser en lo individual, y esto, llevado a lo social, a la acentuación del individuo, ya que los universales, las totalidades, sólo son nombres (nomina) carentes de realidad.

Beuchot escribe:

"El nombre que se daba al derecho subjetivo era, entonces, 'poder' (potestas), esto es, una cualidad del sujeto, a saber, el dominio que tiene sobre las cosas. $\mathrm{O}$, si se quiere, y más propiamente, la potestad engendra el dominio sobre algo, y eso es poseído por el individuo. El paso del ius al poder fue permitido, según hemos visto, por una filosofía nominalista, privilegiadora de lo singular, del individuo, como era la de Ockham. Este fue el primero en defender el derecho subjetivo y en edificarle su teoría." 54

En Ockham el derecho es el poder conforme a la recta razón, y si es poder o potestad, es derecho subjetivo. ${ }^{55}$ Pero para Mauricio Beuchot es

52 Beuchot. "Derechos subjetivos..." Ob. cit. p. 153.

53 Idem Supra. p. 154.

54 Idem Supra. p.156.

55 Idem Supra. p. 157.

Revista da Faculdade de Direito da UFPR, Curitiba, a. 29 , n. 29, 1996, p. 9-37 
todavía una noción de "derecho subjetivo pasivo"; y es hasta el siglo XV que, otro nominalista, Juan Gerson ( +1429), "extrae esa noción de derecho subjetivo activo", pues a diferencia de Ockham, Gerson "sostiene que al dominio pertenece la libertad, la cual es una facultad irrestricta, dada por Dios al hombre. Así, el derecho como dominio lleva a la noción del derecho como libertad o garantía individual." 56

"Gerson fue un gran nominalista, pero también un gran místico, y su vivencia de la libertad divina (para crear y para salvar) y de la libertad humana (aun para pecar) le lleva a ver la libertad como un derecho y el derecho como una libertad. Ya el derecho no está vinculado a un orden moral objetivo ni a un deber -como para Santo Tomás-, su fundamento es la soberanía del individuo... Define el derecho como 'la facultad o potestad que compete a alguien según el dictamen de la recta razón'. Aquí parecería que tan sólo repite el derecho como potestas, que ya hemos encontrado en Ockham (pues en Santo Tomás la potestas pertenecía no al ius, sino al dominium: pero ya está allí el importante añadido de que esta facultad compete o pertenece a alguien. $\mathrm{Y}$, sobre todo, le pertenece por la razón, esto es por la misma naturaleza humana individual, y no sólo por el permiso que concede para algo un superior, en lo cual consistía el derecho subjetivo pasivo." $" 57$

En el siglo XVI son seguidores de Gerson, Joannes Mair y Jacobus Almain, ambos nominalistas, y son quienes trasmiten su pensamiento. Mair fue profesor de Vitoria en el Colegio de Monteagudo de la Universidad de París y tuvo influencia en el dominico; ciertamente no al grado de que Vitoria aceptara la epistemología nominalista, pero influye el nominalismo en su concepción jurídica y de toda la Escuela de Salamanca. Dice Beuchot:

"En el siglo XVI, Vitoria recupera el sentido subjetivo pasivo del derecho que había dado Santo Tomás, no el activo de Gerson. Para Vitoria, tanto los bárbaros o infieles, como los herejes y los cristianos, es decir, todos los hombres, tienen como imágen de Dios la facultad racional; por ella son capaces de dominium sobre sus acciones y sobre sus bienes, i.e. tienen libertad y posesión o gobierno. El derecho individual se da, pero de modo pasivo, porque depende de un orden objetivo de moral y de justicia." 58

Aunque, ciertamente, Vitoria no llega a la concepción del derecho subjetivo como Gerson, en cuanto que facultad, poder, dominio o libertad,

56 Idem Supra.

57 Idem Supra. págs. 157 y 158.

58 Idem Supra. págs. 160 y 161. 
y a que acentúa la noción de lo justo objetivo siguiendo a Santo Tomás, sin embargo, al Profesor del Colegio de San Esteban, la fuerte influencia nominalista, lo hace destacar ya, en algunos textos, la radicación del ius en la persona, como derecho subjetivo, al relacionar el derecho con la posibilidad de padecer injuria, como hemos visto, y a establecer expresamente, con relación a los seres racionales, el derecho que tiene sobre la cosa, cuando que escribe "pueden padecer injuria; luego tienen derecho a las cosas; luego dominio, que no es otra cosa que este derecho."

Y pasando ya a los autores indianos, encontramos, como dice Beuchot, que "Las Casas utiliza, pues, la noción de potestas y dominium, como la pôsesión de algún derecho en sentido subjetivo... Las Casas, aun cuando da preferencia al derecho objetivo, está ya utilizando -con otros vocablos- la noción de derecho subjetivo, incluso en el ámbito del derecho natural. Estos derechos naturales subjetivos son los que corresponden a los derechos humanos." 60

Por último el jesuita granadino, profesor de la Universidad de Coimbra, Francisco Suárez, ya a principios del siglo XVII combina elementos de Santo Tomás con una concepción cercana a la de Juan Gerson: Beuchot siguiendo a Hervada, sostiene que con Suárez se produce un cambio respecto al sentido estricto y primario de la palabra derecho, ius. De ser primordialmente la cosa justa pasa a designar el derecho sobre la $\cos a$, el derecho subjetivo o facultad moral sobre la cosa. En esta misma línea, Vela Sánchez escribe:

"Pero además en Suárez, y lo destacamos desde el principio en su elogio, la ley es derecho objetivo, sí, norma de convivencia, pero es también e inseparablemente facultas agendi, poder personal de obrar, pero poder objetivo y objetivado en cuanto a esfera real objetiva reservada y protegida para cada sujeto, en cuanto a autonomía personal objetiva. Si por tanto, y entendido rectamente, en el concepto de la ley se encuentran sintetizados estros tres aspectos: real, normativo y personal, podemos afirmar que Suárez emplea indistintamente los términos de ley y derecho." 61

59 Las relecciones juridicas de Vitoria. Ob. cit. p. 72

60 Idem Supra. págs. 163 y 165.

61 Luis Vela Sánchez. "Suárez, Teólofo y Filósofo del Derecho", estudio preliminar en la obra de Francisco Suárez, S.J. Tratado de las Leyes y de Dios Legislador, edición bilingüe de De Legibus, versión española de José Ramón Eguillor Muniozguren. Ed. Instituto de Estudios Políticos. Madrid, 1967. págs. XXXIII y XXXIV.

Revista da Faculdade de Direito da UFPR, Curitiba, a. 29, n. 29, 1996, p. 9-37 
Veamos que es lo que Suárez dice en cuanto al concepto de derecho, ius:

"En primer lugar, ius puede significar todo cuanto es equitativo y conforme a la razón, que es -como quien dice- el objeto común de la virtud en general. En segundo lugar, ius puede significar la equidad que a cada uno se le debe en justicia, y este es el significado más corriente, pues ius, tomado en este sentido, puede referirse, ante todo, a la justicia propiamente dicha. Por eso dijo Santo Tomás que este es el primer concepto y significado del ius, y de ahí deduce lógicamente que ius no es la ley sino más bien lo que la ley prescribe o mide.

Según el último y más estricto significado de ius, con toda propiedad suele llamarse ius al poder moral que cada uno tiene sobre lo suyo o sobre lo que se le debe; así se dice que el dueño de una cosa tiene derecho sobre la cosa y que un obrero tiene derecho al salario, por razón de lo cual se dice que es digno de su recompensa. Este significado es frecuente, no sólo en derecho sino también en la Escritura." 62

Beuchot concluye así su recorrido histórico-genealógico, con reláción a los derechos subjetivos, base de la concepción moderna de los derechos humanos:

“... la noción de derecho subjetivo, aun cuando tiene antecedentes en la misma Antigüedad y sobre todo en la Edad Media, se da propiamente en Ockham; este inicia lo que se ha llamado derecho subjetivo pasivo, y un seguidor de la escuela nominalista, el canciller Gerson, añade lo que se ha denominado derecho subjetivo activo, que es el que, a través de Mair y Almain, llega a Vitoria y a la Escuela de Salamanca, encontrando cierta reticencia en Soto, pero dándose de alguna manera en Las Casas y, sobre todo, en Suárez, que es quien trasmite este concepto a la modernidad, en la que encuentra su desarrollo cabal. ${ }^{, 63}$

El concepto de Derecho (ius o jus), es análogo y no unívico; por lo que se abstrae su realidad por medio del conocimiento que proporciona la analogía. Así Derecho es un término que se predica, en forma análoga, de varias realidades: la ley, norma o derecho objetivo; la facultad, potestad moral o derecho subjetivo; lo justo objetivo, esto es la conducta o cosa que

62 Suárez. Ob. cit. Lib. I, Cap. 2, Nos. 4 y 5. p. 11.

63 Beuchot. "Derechos subjetivos..." Ob. cit. p. 167. 
se debe a otro; y la llamada ciencia del Derecho, como conocimiento sistemático y controlado de la juridicidad. ${ }^{64}$

Si esto es así, tenemos que, en nuestro concepto, desde Santo Tomás el Derecho se concibe como facultad, sólo que con una carga muy fuerte sobre el analogado principal de la juridicidad que para el Aquinate es la objetividad de lo justo que es la que le da sentido a unos derechos subjetivos casi diluidos. La Escuela de Salamanca y los hispanoamericanos, por la influencia nominalista, tienen una mayor claridad con relación a los derechos subjetivos y acentúan su importancia como derechos naturales humanos, aunque, fieles con esto a Santo Tomás, siguen teniendo como analogado principal del Derecho lo justo objetivo. Los derechos subjetivos no se pierden, no se diluyen, aunque estén supeditados a la objetividad de la justicia, como analogados secundarios; por eso puede aparecer ya una noción fuerte de derechos humanos. Y Suárez, sin perderse en subjetivismos, ni adoptando un principio social individualista, resaltando la debida importancia del Derecho como lo justo objetivo, prioriza la noción del Derecho como poder moral sobre lo suyo, haciendo del derecho subjetivo el analogado principal del Derecho. Los derechos humanos pasan así a convertirse en la noción más propia de la juridicidad. ${ }^{65}$

Mauricio Beuchot ha venido sosteniendo, además, que para la Escuela de Salamanca y los hispanoamericanos -especialmente Las Casasfue esencial en su concepción de los derechos humanos "el realismo en el tema de los universales," ya que eso les impulsaba "a conceder

Quien ha profundizado lo relativo a la analogía del Derecho ha sido Efraín González Morfín en "Analogía, ser del Derecho y ser de la Sociedad", en Jurídica $N^{\circ}$ 6. Anuario del Departamento de Derecho de la Universidad Iberoamericana. México, julio de 1994, págs. 281-350; y en "Filosofía del Derecho. Ontología", en Revista Jurídica Jaliciense $N^{\circ} 9$ del Departamento de Estudios e Investigaciones Jurídicas de la Universidad de Guadalajara. Guadalajara, mayo-agosto de 1994, págs. 129-153. En el primer trabajo sostenía que "la realidad original o analogado principal es la facultad o potestad moral de la persona sobre lo suyo" (págs. 292 y 293); ya en el segundo trabajo sostiene que el analogado principal es lo justo objetivo, porque "la facultad y las normas existen para que las personas humanas, individuales o asociadas, puedan lograr, conservar o promover lo justo objetivo que se les debe en los distintos ámbitos de la existencia humana." (p. 152).

65 Sobre esta cuestión tan polémica referida al analogado principal y al objetivismo o subjetivismo prioritario en el Derecho, además de las obras ya citadas, puede verse: Louis Lachance. El Derecho $y$ los derechos del hombre. Ed. Rialp. Madrid, 1979; Lachance reafirma la objetividad del Derecho en Santo Tomás incluso trasladando el analogado principal al derecho objetivo como ley natural o positiva y no a lo justo objetivo (p. 200). Walter Redmond. "Una lógica del compromiso social", en Analogía Filosófica, México, enero-junio de 1994. págs. 3-39. Desde los presupuestos de la lógica presenta la filosofía jurídica de Santo Tomás siguiendo a Joseph Gredt, analizando los distintos sentidos del jus.

Revista da Faculdade de Direito da UFPR, Curitiba, a. 29, n. 29, 1996, p. 9-37 
universalidad real a la dignidad de todos los individuos de la especie humana". ${ }^{66}$ Por esa razón los indios y luego después los negros ${ }^{67}$ forman parte de esa universalidad necesaria en los llamados derechos humanos; concepto universal al cual no llegaron los individualistas liberales de la Escuela del Derecho Natural en la Ilustración, con su idea restringida de los derechos humanos.

Para completar este recorrido genealógico de la concepción de los derechos humanos de la tradición hispanoamericana, nos falta reiterar aquí, que esa visión de los derechos del ser humano parte desde los pobres, desde aquellos que les son violados sus derechos, desde los que padecen la injusticia, estando implícita la noción bíblica del Derecho como mispat (liberación del oprimido). Como dice Gustavo Gutiérrez:

"En una palabra, derechos humanos sin duda, pero no en una perspectiva liberal y formalmente igualitaria, sino en la línea del derecho de los pobres, condenados a la muerte y a la destrucción por el opresor en busca de oro. Del derecho de los pobres nos habla en nuestros días la conferencia episcopal de Medellín, haciéndose eco de la experiencia y la reflexión de la Iglesia que vive en América Latina. En este sentido puede afirmarse que estamos ante un derecho nuevo, de hondas raíces -como decíamos más arriba- no sólo teológicas sino bíblicas. No hay aquí, en la afirmación del derecho de los pobres, pérdida de universalidad de los principios como algunos parecen temer, lo que hay es verdadera universalidad a través de la ganancia en concreción histórica y en realismo evangélico; bases de toda auténtica profecía." $" 68$

Creemos que la importancia de la tradición teórica hispanoamericana de los derechos humanos es enorme y debe ser rescatada, no sólo como curiosidad histórica, sino como una concepción alternativa de los derechos humanos, según piensa Fernando Rovetta:

"La sutileza y la eficacia con la que hoy se violan los derechos humanos de inmensas mayorías, v. gr. el hambre, a pesar de contar con medios tecnológicos que podrían evitar tales violaciones, puede llevarnos a plantear

66 Beuchot. "Bartolomé de Las Casas..." Ob. cit. p. 48.

67 Con relación al reconocimiento de los derechos de los negros en Las Casas véase De la Torre Rangel. Ob. cit. págs. 104-106. Y en cuanto a la defensa de los derechos de los negros en otros autores de la tradición teórica hispanoamericana: Miguel Angel Fernández Delgado y Silvio Zavala. "La defensa de los derechos humanos en hispanoamérica", en A nuario Mexicano de Historia del Derecho VI-1994, Ob. cit. págs. 116-119.

Gutiérrez. Ob. cit. p. 70. 
en que medida los modelos históricos de derechos humanos están agotados, o tienen en su raíz -individualista y economicista- el germen de su destrucción."

"Plantear la conveniencia de rastrear en la historia un modelo alternativo, quizá frustrado en el momento mismo de su gestación, surge como una respuesta ante los hechos contrastables en el sur, queda por ver si cinco siglos después las universidades españolas y americanas pueden volver a ser caja de resonancia de los 'alaridos de tanta sangre humana' (Las Casas)."

69 Rovetta. Ob. cit. p. 174.

Revista da Faculdade de Direito da UFPR, Curitiba, a. 29, n. 29, 1996, p. 9-37 